\title{
Provision of Teaching and Learning Materials that Enhance Participation of Students with Special Educational Needs in Inclusive Schools at Pokuase in the Greater Accra Region
}

\author{
Michael Nyavor \\ Methodist College of Education, Akim Oda, Ghana
}

\begin{abstract}
The study focused on investigating teaching and learning materials teachers provide to enhance participation of students with special educational needs in teaching and learning at Pokuase in the Greater Accra Region of Ghana. The study employed the descriptive survey design. Purposive and simple random sampling techniques were used to select the sample size of 112 respondents. Descriptive statistical method was used to analyse questionnaire data for the study. Results from the study revealed that, teachers provide teaching and learning materials of all kinds during teaching and learning. However, some of these materials do not cater for the unique needs of all learners especially those with special educational needs. Instructional materials such as tape recorders and text in braille were not provided, computers were not adapted to enhance easy access for pupils with special educational needs. The study recommended that teachers provide materials to include tape recorders, text in Braille, materials that are bold with good colour contrast and adapted computers for easy access especially to those with special educational needs.

Purpose of the study

The study sought to investigate teaching and learning materials teachers provide to enhance learning among pupils especially those with special educational needs in inclusive classrooms.

Keywords: provisions, special educational needs, teaching and learning materials, assistive technology.

DOI: $10.7176 / \mathrm{JEP} / 11-4-01$

Publication date: February $29^{\text {th }} 2020$

\section{Introduction}

Every student can learn irrespective of his/her disability, sex, race provided the unique needs are addressed during teaching and learning process. Inclusive education as an approach implies all learners, with or without disabilities, to be able to learn together through access to common pre-school provisions, schools and community educational setting with an appropriate network of support services, which can be possible only in a flexible education system that assimilates the needs of diverse learners and adapts itself to meet these needs, ensuring that all stakeholders in the system are comfortable with diversity and see it as a challenge rather than a problem. There are many factors that borders on the effective inclusion of students with special educational needs in inclusive schools as far as teaching and learning is concerned. However, this paper sought to investigate teaching and learning materials teachers provide to enhance the participation of students with special educational needs in learning. Teaching and learning materials has been considered to include assistive devices in this paper.
\end{abstract}

The use of teaching and learning materials to enhance participation of students with special educational needs in learning

The term teaching and learning materials comprise all the materials and physical means an instructor might use to implement instruction and facilitate students achievement of instructional objectives. Teaching and learning materials may aid a student in concretizing a learning experience so as to make learning more exciting, interesting and interactive. Teaching and learning materials are materials in various forms ranging from pictures, realia, objects, models, specimens, printed materials like textbooks, workbooks, computers which could be used to influence the participation and understanding of students in learning. Other materials include; chalkboards, flannel of felt boards, felt pens, spectacles, handheld magnifiers, braille machines, hand frames and stylus, braille sheets and bulletin, still pictures like photographs and illustrations, charts, graphs, maps, large print books and globes, posters and diagrams, reading stand. It can be concluded that instructional materials can be classified as prints, audio, audio-visuals, visuals and electronic interactive. Most of the materials can apply to both students with/out special educational needs during teaching and learning. However, some of the materials needs to be adapted to meet the unique needs of students with special educational needs to enhance their learning.

In using materials both electronic and non-electronic, the teacher needs to make sure they appeal to the senses of students. This could help arouse interest and sustain it in learning. This process also make learning meaningful to learners. The sensory theory is of same view to see teaching and learning process stimulate the senses of students. Laird (1985) suggests that learning occurs when the senses of sight, hearing, touch, smell and taste are stimulated. This is easy if you are teaching a practical session. However, in making concepts clearer to 
learners, there is the need to teach in a way that appeal to all the senses whether the lesson is practical or theoretical. Whenever possible, link theory to practice, and use practical activities based around the subject and the areas of interest of your learners. If you can make your session fun and interesting, relating to all the senses, it will help your learners remember the topics better.

Teaching and learning materials are categorised based on a continuum and classified as low-tech, mediumtech or high tech based on the level of sophistication in features, cost, level support needed to use (Chambers \& Berlach, 2015). Chamber and Berlach (2015) describe low and medium-tech devices as requiring only basic instruction or and not overly complicated to operate. Low tech devices are often not electronic, simple to make and acquire such as communication boards, visual schedules, highlighter, word rings. Medium tech devices are reasonably complicated such as talking calculators, visual timers, tablets and IPad applications. Lastly, high tech devices are most complex and often specialized to accommodate a specific function and requires more training, which can include: software (Inspiration mapping), augmentative communication devices, Smartboards (Chamber \& Berlach, 2015).

Engelbrecht and Green (2007), Florian (2008), Stubbs (2008), emphasized that teaching resources and materials as well as the school facilities, are part of the contributing factors in supporting inclusive practice. Stubbs maintained that 'education for all' will not work unless there is more grassroots participation and effective allocation of resources. More resources such as classrooms, laboratories, learner and teacher support material and quality instruction need to be directed to and ensure that children learn effectively. When a school is well equipped with basic teaching and learning resources, it makes teachers' jobs easier and the learning outcomes of the children will improve.

Low-tech materials that could be used in teaching students is sorting tray. Sorting trays are made from plywood or aluminium plates in a rectangular form. As trays they have hollow in them to serve as a good receptacle for various materials. Usually teachers fill these trays with colourful beads, geometric shapes, counters, cowries, and pebbles among others. This tray enables pupils to sort out items in terms of similarity in texture, shape, weight, and colour (Ocloo, 2003).

Students with special educational needs, especially those with orthopaedic disorders, use adaptive devices to hold papers in place, for example clips and desks are at an appropriate height for the student and are adjustable. Reading stands can also be substituted for non-adjustable tables to enhance the posture and distance from which students with disabilities will prefer to read (Ocloo, 2003).

Teachers may use a variety of textures, models, shapes, foods, ingredients, to either replace visual material, or supplement it. Using a variety of sensory inputs such as words, pictures, and sounds enhances the understanding of students and sustain their interest in lesson. It is recommended that a combination of simple, self-made material and ready-made commercially produced teaching aids is utilized (Ajayi \& Faremi, 2008).

Some of these materials or devices are sophisticated therefore require high amount of power in the form of electricity in order to operate. These include video-tapes, filmstrips, overhead projectors and opaque projections, audio aids like radio, record players and tape recorders, audio-visual aids in the form of motion pictures, computers, television, closed circuit television, talking calculator, and talking books among others. These aids are usually termed assistive technology (Ajayi \& Faremi, 2008).

Many learners who experience barriers to learning may need to rely on technology to facilitate access and participation in the general classroom. This technology is available in the form of assistive devices. Some of these resources are sophisticated and expensive computers and word processors that offer learners independence and the opportunity to enjoy maximum success. Learners may also benefit from using digital personal organisers, multi-media such as film clips and assistive devices such as microphones and Braille translators (Walton, Nel, Hugo, \& Muller, 2009).

Provenzo, Brett, and McCloskey (1999) explained how computers, adaptive computer interfaces, and specialized software are especially important to children with disabilities. They believed output devices such as monitors, printers, and speakers can be adapted for children with disabilities in order to encourage access. Adaptive input devices enable children with special needs to activate and send information: keyboards can be modified, and alternative keyboards (usually larger in size) can provide access. Touch Windows, a touchsensitive screen, is a direct way for students with disabilities to interact with the computer. Output devices such as monitors with enlarged text and graphics, printers producing large print or Braille, tactile devices produced using Braille, output hardware, and speakers are important for children with disabilities and also help meet the criteria mandated by the IDEA.

Other categories of students with special needs may rely more on the use of tactile representation in learning. Tactile representations may include partial objects, more abstract tactile symbols and Braille. This access method would utilize devices that can support tactile symbols such as the GoTalk SuperTalker, which activates when pressed. This does not typically include touchscreen devices. Motor memory/tactile guide devices without tactile symbols but with tactile guides such as keyguards are paired with markers to guide the user. Bluetooth Braille keyboards paired with text-to-speech software may also be included in this category, as well as 
voice output devices and SGDs with keyguards and consistently placed language to support motor memory for the location of vocabulary (UNICEF, 2018).

Students with communication problems can benefit from augmentative communication devices, which are computers equipped with speech synthesizers that can type, text, and produce speech heard by everyone. Textto-speech functionality can assist a variety of students, including those who are motivated by more advanced materials but are frustrated by reading comprehension difficulties; those who will profit from the reinforcement of both print and oral reading; and those who hate to read but are willing to listen. It can be used with a whole class, with groups, or with individual students for previewing new information or as part of a final proofreading exercise. Kindergarteners can listen to individual letters and work in an exploratory fashion. Talking text is an important additional tool for supporting comprehension for some students, and several research studies have identified its promise for helping students with reading disabilities comprehend written materials (National Institute of Child Health and Human Development, 2000). Text-to-speech technology has been found useful for students with vision impairments and for those with reading difficulties. Specifically, this technology has been found to significantly improve the reading comprehension of students with reading difficulties (Anderson-Inman \& Horney, 2007).

Students with learning disabilities can compensate for poor handwriting, spelling, and grammatical skills using word-processing equipment. The dyslexic or cognitive impaired student may benefit, in particular, from the use of simpler language or alternative text formats, such as Easy Read, as well as from the clear and logical layout of an uncluttered structure of information. Activating just punctuation and capitalization might be more helpful with younger children, while turning on only passive sentences, possessives and plurals, or subject-verb agreement could be more helpful with older students. These devices can also be programmed with words and phrases for particular situations (UNESCO, 2006). There is evidence on the impact on the acquisition of language especially in the case of students with learning disabilities. Students with language-related disabilities showed positive effects for word recognition, comprehension, and fluency when using digital texts with synthetic, syllable- or letter name-level synthetic speech transformations (Elbro, Rasmussen, and Spelling (1996).

In addition, there are other assistive technology devices that are needed to provide academic services to students with special needs. These include text-to-braille translation software thus programs that translate print to braille, embosser thus braille printer, a device used to emboss text in braille, Scanner with Optical Character Recognition (OCR) software thus a device used to convert paper text into digital format. Optical Character Recognition OCR is software that converts the image of the text on pages that are being scanned and turns it into e-text, image simplifying software programs that convert images from visual to textual by simplifying their content, image embossing devices hardware that makes flat print images tactually accessible, colour copier with enlarge function a device that allows enlargement of print material, text-to-audio software programs that convert electronic text into an audio format. Some programs also save files as portable audio files like, voice recording software programs that allow digital voicing recording and editing. Files can be saved in various formats and subsequently either listened to on the computer, or transferred to portable media players. In addition to the above solutions, various simple tools and materials can complete the inventory of adaptive material (Wiazowski, 2009). Cullen, Richards, and Frank (2008) conducted a study to determine whether computer software would help students with disabilities improve their performance in writing. A multiple baseline design was used to study seven fifth grade students with mild disabilities in three phases: baseline, intervention using a talking word processor, and intervention using word prediction software in conjunction with a talking word processor. The results showed that five students out of seven in the study improved the number of words produced in the two intervention phases, while the number of words produced decreased with the other two students in both intervention phases compared with the baseline phase. The group mean indicated that there was an improvement in the number of words produced. There were improvements in the number of misspelled words across phases, both individually and in the group mean. In general, the results showed that the impact on most of the seven students was positive.

\section{Methodology}

The descriptive survey design was adopted for study to investigate teaching and learning materials teachers provide to enhance the participation of students with special educational needs in learning. Descriptive survey research design set out to describe and to interpret what is over a period of time (Cohen, Manion, \& Morrison, 2003). In other words, descriptive survey set out to give current account of a particular phenomenon. The population for the study was 950 which comprised all teachers and students with/without special educational needs in the three selected inclusive pilot basic schools at Pokuase in the Greater Accra Region. The population is high because the schools involved in the study are cluster.

A sample of 112 respondents was selected comprising all teachers and students with special educational needs from three pilot inclusive schools. In all, ninety-seven (97) teachers and fifteen (15) students with special educational needs from the three schools were involved. Five students with special educational needs were 
selected from each school. The purposive and simple random sampling techniques were used to select teachers and students for the study. Teachers were sampled strictly by purposive sampling technique where the researcher solicits from persons with specific characteristics to participate in a research study (Johnson \& Christensen, 2004). The census sample was employed where all teachers from the three selected pilot schools were involved in the study. The census sample was used because every teacher had, at least, one or more students with special educational needs in his or her class. Purposeful sampling was used because it economizes time and specific information can be obtained at a much reduced cost and time.

\section{Instrumentation}

In this study, questionnaire and interview were used for data collection. The questionnaire was used for teachers. The questionnaire had 30 close-ended items. The questionnaire contained two sections, the demographic and items based on the major themes in the research questions for the respondents. The items were built on a 4 likert scale points ranging from Strongly Agree $(\mathrm{SA})=4$; Agree $(A)=3$; Disagree $(\mathrm{D})=2$; and Strongly Disagree (D) $=1$. The respondents were to choose one options from which were closer to their own opinions. The questionnaire were constructed to cover the key themes raised in the research questions.

\section{Procedure for data collection}

The researcher sought permission from heads of the three selected schools in writing of which the head subsequently informed the teachers about the study in order to solicit their cooperation and assistance. After the permission was granted, the researcher arranged with the respondents the day of responding to the items. This is consistent with what Creswell (2005) says that it is important to respect the site where a research takes place.

The researcher went to the schools of study to administer the questionnaires personally to ensure maximum response. The researcher explained the purpose of the study, and re-assured the participants of the necessary confidentiality on the information to be gathered. The two instruments were administered on different days. Forty (40) minutes was allotted for responding to the questionnaires. Answered questionnaires were retrieved on the same day.

\section{Method of data analysis}

Descriptive approach was used for analysing data from the questionnaire. This was influenced by the nature of the research questions. The statistical package for service solutions [SPSS] version 20 software was used in analysing data from the questionnaire. The data were initially analysed into frequency distribution and results were further converted into percentages for easy discussion. Descriptive statistics, in the form of percentages and frequencies, were employed to analyze the collected data. Frequency tables were constructed in line with the variables raised in the research questions to support the data analysis.

\section{Presentation of Results and Discussion of Findings}

What teaching and learning materials are available to enhance the participation of pupils with special educational needs in learning in inclusive classrooms?

\begin{tabular}{|c|c|c|c|c|c|}
\hline Statement & SA & $\mathbf{A}$ & D & SD & TOTAL \\
\hline $\begin{array}{l}\text { 1. Real objects are used during the } \\
\text { teaching and learning process }\end{array}$ & $\begin{array}{l}53 \\
(55 \%)\end{array}$ & $\begin{array}{c}39 \\
(40 \%)\end{array}$ & $\begin{array}{c}5 \\
(5 \%)\end{array}$ & $\begin{array}{c}0 \\
(0 \%)\end{array}$ & $\begin{array}{c}97 \\
(100 \%)\end{array}$ \\
\hline $\begin{array}{l}\text { 2. Models of objects are used in } \\
\text { teaching pupils to enhance their } \\
\text { understanding of concepts }\end{array}$ & $\begin{array}{c}38 \\
(39 \%)\end{array}$ & $\begin{array}{c}52 \\
(54 \%)\end{array}$ & $\begin{array}{c}7 \\
(7 \%)\end{array}$ & $\begin{array}{c}0 \\
(0 \%)\end{array}$ & $\begin{array}{c}97 \\
(100 \%)\end{array}$ \\
\hline $\begin{array}{l}\text { 3. Tactile materials are used during } \\
\text { the teaching and learning process }\end{array}$ & $\begin{array}{c}17 \\
(18 \%)\end{array}$ & $\begin{array}{c}5 \\
(5 \%)\end{array}$ & $\begin{array}{c}17 \\
(43 \%)\end{array}$ & $\begin{array}{c}5 \\
(34 \%)\end{array}$ & $\begin{array}{l}97 \mid \\
(100 \%)\end{array}$ \\
\hline $\begin{array}{l}\text { corders are provided to pupi } \\
\text { ecial educational needs to } \\
\text { essons during teaching } \\
\text { ving glasses are provided }\end{array}$ & $\begin{array}{l}\text { ls } \\
15 \\
(15 \%)\end{array}$ & $\begin{array}{l}20 \\
(21 \%)\end{array}$ & $\begin{array}{l}45 \\
(46 \%)\end{array}$ & $\begin{array}{l}17 \\
(18 \%)\end{array}$ & $\begin{array}{c}97 \\
(100 \%)\end{array}$ \\
\hline to $\mathrm{p}$ & $\begin{array}{l}13 \\
(13 \%)\end{array}$ & $\begin{array}{c}2 \\
(2 \%)\end{array}$ & $\begin{array}{c}31 \\
(32 \%)\end{array}$ & $\begin{array}{c}51 \\
(53 \%)\end{array}$ & $\begin{array}{c}97 \\
(100 \%)\end{array}$ \\
\hline $\begin{array}{l}\text { npairments are } \\
\text { Braille }\end{array}$ & $\begin{array}{c}0 \\
(0 \%)\end{array}$ & $\begin{array}{c}10 \\
(10 \%)\end{array}$ & $\begin{array}{c}69 \\
(71 \%)\end{array}$ & $\begin{array}{c}18 \\
(19 \%)\end{array}$ & $\begin{array}{c}97 \\
(100 \%)\end{array}$ \\
\hline $\begin{array}{l}\text { 7. Pupils with low vision are } \\
\text { provided with text in large print } \\
\text { 8. Computers are adapted with }\end{array}$ & $\begin{array}{c}40 \\
(41 \%)\end{array}$ & $\begin{array}{c}20 \\
(21 \%)\end{array}$ & $\begin{array}{c}21 \\
(22 \%)\end{array}$ & $\begin{array}{c}16 \\
(16 \%)\end{array}$ & $\begin{array}{c}97 \\
(100 \%)\end{array}$ \\
\hline $\begin{array}{l}\text { pupils } \\
\text { eds }\end{array}$ & $\begin{array}{c}0 \\
(0 \%)\end{array}$ & $\begin{array}{c}5 \\
(5 \%)\end{array}$ & $\begin{array}{c}40 \\
(41 \%)\end{array}$ & $\begin{array}{l}52 \\
(54 \%)\end{array}$ & $\begin{array}{l}97 \\
(100 \%)\end{array}$ \\
\hline $\begin{array}{l}\text { 9. Adjustable tables are available for } \\
\text { pupils with physical disabilities }\end{array}$ & $\begin{array}{c}6 \\
(6 \%)\end{array}$ & $\begin{array}{c}9 \\
(9 \%)\end{array}$ & $\begin{array}{c}60 \\
(62 \%)\end{array}$ & $\begin{array}{c}22 \\
(23 \%)\end{array}$ & $\begin{array}{c}97 \\
(100 \%)\end{array}$ \\
\hline
\end{tabular}


It is evident from the results that teachers make use of real objects during the teaching and learning process to enhance the understanding of pupils in learning. This also sustain the interest of learners in the teaching. Teachers provide models and use them for teaching and learning in times they could not locate real objects or feel the real object is dangerous to be brought in real life. Most of the teachers could not provide tactile materials to compensate for pupils who find it difficult to visualise materials due to their special educational needs. This debunk Ajayi and Faremi (2008) assertion that teachers in inclusive settings need to augment their teaching with resources. It is only then that their teaching can be meaningful and beneficial to children with special education needs.

It was also clear from the results that teachers could not provide tape recorders to augment the needs of students with special educational needs such the low vision. Majority of the pupils identified to have visual problems are not provided with spectacles or magnifying glasses to enhance their participation in lessons. This could affect their learning. Moreover, the findings of the study brought to the fore that, most of the teachers could not provide text in Braille for pupils with visual impairments to enhance their learning. This contrast the assertion of UNESCO (2006) that, text be translated into an audible format by specially designed screen-reading devices or made accessible by the means of printed Braille text for pupil with special educational needs. The results indicated that, pupils with low vision are provided with text in large print by teachers to enhance their participation in learning. Regarding the use of large print text, it was evident from the results that teachers provide pupils with low vision to enhance their participation in lesson. The schools have few computers but not adapted with software such as JAWS to enhance the use by pupils with special educational needs. This debunks the assertion of Provenzo, Brett, and McCloskey (1999) who explained how computers, adaptive computer interfaces, and specialized software are especially important to children with disabilities.

Finally, pupils with physical disabilities are not provided with adjustable tables or reading stand to enhance their posture during teaching. This contrast the assertion of (Ocloo, 2003) students with special educational needs, especially those with orthopaedic disorders, use adaptive devices to hold papers in place, for example clips and desks are at an appropriate height for the student and are adjustable. Reading stands can also be substituted for non-adjustable tables to enhance the posture and distance from which students with disabilities will prefer to read.

\section{Findings}

The findings revealed that teachers provide teaching and learning materials to facilitate learning among pupils. They provide real objects and models to aid the understanding of pupils in lessons. However, much is not done to adapt other teaching and learning materials, to meet the unique needs of pupils with special educational needs. Computers do not have software to enhance pupils participation in lessons. Little effort is put in place to provide tactile materials to support teaching and learning of pupils with special educational needs.

\section{Conclusion}

From the study, much is not done to adapt teaching and learning materials, or use assistive technologies to support teaching and learning of pupils in inclusive schools.

\section{Recommendations}

Teaching and learning materials should be provided to include tape recorders, adjustable or reading stand, text in Braille, adapted computers for easy access to pupils with special educational needs.

\section{REFERENCES}

Anderson-Inman, L. \& Horney, M. A. (2007). Supported eText: Assistive technology through text transformations. Reading Research Quarterly, 42, 153-160.

Ajayi, L. A., \& Faremi, M. F. (2008). Resource availability and pupils learning outcome in primary schools in Ekiti State, Nigeria. Ghana Journal of Education and Teaching. 1(5), 131-135.

Chambers, D., \& Berlach, R. G. (2015). Assistive technology and teacher assistants. (pp. 219-239) Emerald Group Publishing Limited.

Cohen, J., Manion, L., \& Morrison, K. (2003). Designing a qualitative study. Newsbury Park: CA Sage.

Creswell, J. W. (2005). Educational research planning, conducting and evaluating qualitative and quantitative research. Ohio: Pearson and Merrill Prentice -Hall.

Cullen, J., Richards, S. B., \& Frank, C. (2008). Using software to enhance the writing skills of students with special needs. Journal of Special Education Technology, 23, 33-44.

Elbro, C, Rasmussen, I., \& Spelling, B. (1996). Teaching reading to disabled readers with language disorders: A controlled evaluation of synthetic speech feedback. Scandinavian Journal of Psychology, 37, 140-155.

Engelbrecht, P., \& Green, L. (2007). Responding to the challenges of inclusive education in Southern Africa. Pretoria: Van Schaik. 
Florian, L. (2008). The SAGE handbook of special education. London: Sage Publications.

Johnson, B., \& Christensen, L. (2004). Educational research: Quantitative, qualitative and mixed approaches $\left(2^{\text {nd }} E d.\right)$. Boston, MA: Pearson Education, Inc.

Laird, D. (1985). Approaches to Training and Development. Harlow: Addison Wesley.

National Institute of Child Health and Human Development (2000). Teaching children to read: an evidencebased assessment of the scientific research literature on reading and its implications for reading instruction. Washington, DC: U.S: Government Printing Office.

Ocloo, M. A. (2003). Effective education for persons with visual impairments in Ghana. Winneba: University of Education, Department of Special Education.

Provenzo, E. F., Brett, A., \& McCloskey, G. N. (1999). Computers, curriculum, and cultural change. Mahwah, NJ: Lawrence Erlbaum Associates.

UNESCO (2006). Guidelines for inclusion: Ensuring access to education for all. Paris: UNESCO.

UNICEF (2018). Inclusive Education Strategies: A Textbook. USA: University of Minnesota.

Stubbs, S. (2008). Inclusive education where there are few resources. Norway: Atlas Alliance.

Walton, E., Nel, N., Hugo, A., \& Muller, H. (2009). The extent and practice of inclusive education in independent schools in South Africa. South African Journal of Education, 29 (1), 1-12.

Wiazowski, J. (2009). Assessing students' needs for assistive technology. Unpublished. 